Dom. Cien., ISSN: 2477-8818

Vol. 4, núm. 1, enero, 2018, pp. 352-361

\title{
Observaciones acerca del uso del hidróxido de calcio en la endodoncia
}

\author{
Observations about the use of calcium hydroxide in endodontics \\ Observações sobre o uso de hidróxido de cálcio na endodontia
}

José P. Muñoz-Cruzatty ${ }^{\mathrm{I}}$

jose.munoz@uleam.edu.ec

Shirley X. Arteaga-Espinoza II

shirleyximenaa@gmail.com

Alcira M. Alvarado-Solórzano III

alciraas@gmail.com

Recibido: 14 de septiembre de 2017 * Corregido: 28 de octubre de 2017 * Aceptado: 25 noviembre de 2017

I. Magister en Gerencia y Auditoria de Servicios de Salud Bucal, Doctor en Odontología, Diplomado Superior en Odontología Integral, Docente de la Universidad Laica Eloy Alfaro de Manabí, Manta, Ecuador.

II. Magister en Gerencia Educativa, Doctor en Odontología, Docente de la Universidad Laica Eloy Alfaro de Manabí, Manta, Ecuador.

III. Magister en Gerencia y Auditoria de Servicios de Salud Bucal, Odontóloga, Docente en la Universidad Laica Eloy Alfaro de Manabí, Manta, Ecuador. 


\title{
Resumen
}

Se realizó una revisión bibliográfica, con el objetivo de describir los efectos del hidróxido de calcio, los procedimientos clínicos en los cuales se utiliza y su aplicación en la terapia endodóntica. La investigación científica situó al hidróxido de calcio (HC), desde hace varias décadas, como elección de uso con alta posibilidad predictiva en la terapia pulpar para preservar su vitalidad y lograr la acción de estímulo en la remineralización de los tejidos dentales, en condiciones clínicas tales como: recubrimientos pulpares, apexificación, reabsorciones internas, entre otros. La mayoría de los autores refirieron resultados exitosos al aplicar este medicamento.

Palabras clave: endodoncia; hidróxido de calcio.

\begin{abstract}
A literature review was carried out, with the objective of describing the effects of calcium hydroxide, the clinical procedures in which it is used and its application in endodontic therapy. Scientific research has placed calcium hydroxide (HC), for several decades, as a choice of use with high predictive potential in pulp therapy to preserve its vitality and achieve the action of stimulation in the remineralization of dental tissues, under clinical conditions such as: pulp coatings, apexification, internal resorption, among others. Most of the authors reported successful results when applying this medication.
\end{abstract}

Keywords: endodontics; calcium hydroxide.

\section{Resumo}

Realizou-se uma revisão da literatura, com o objetivo de descrever os efeitos do hidróxido de cálcio, os procedimentos clínicos em que é utilizado e sua aplicação na terapia endodôntica. A pesquisa científica colocou o hidróxido de cálcio $(\mathrm{HC})$, durante várias décadas, como uma escolha de uso com alto potencial preditivo na terapia de polpa para preservar sua vitalidade e alcançar a ação de estimulação na remineralização de tecidos dentários, em condições clínicas tais como: revestimentos de polpa, apexação, reabsorção interna, entre outros. A maioria dos autores relatou resultados bemsucedidos ao aplicar este medicamento.

Palavras chave: endodontia; hidróxido de cálcio. 


\section{Introducción}

El complejo dentino pulpar como su nombre lo indica, es una estructura integrada por la dentina y la pulpa dental. Estas tienen en común que: juntas conforman una unidad estructural, dado que las prolongaciones de los odontoblastos están incluidas en la dentina, conforman una unidad funcional, ya que la pulpa mantiene la vitalidad de la dentina, y la dentina protege a la pulpa, comparten un origen embrionario común, pues ambas derivan del ectomesenquima que forma la papila del germen dentario. Por estas razones se considera a la dentina y a la pulpa en su conjunto como una sola estructura integrada, denominada complejo dentino-pulpar ${ }^{1}$.

Los procedimientos de antisepsia en endodoncia cobran una significación especial, la ausencia de gérmenes tiene una importancia capital en el buen resultado de los tratamientos realizados en el campo de esta especialidad. Numerosos han sido los medicamentos que se han empleado con este fin. Dentro de esta amplia gama de agentes se encuentra el hidróxido de calcio $(\mathrm{CaOH})$, cuyo uso en odontología ha despertado recientemente un interés considerable ${ }^{2}$.

Aunque la referencia más antigua sobre el $\mathrm{CaOH}$ se atribuye a Nygren en 1838, su desarrollo en la práctica odontológica actual comienza en 1930 cuando BW Hermann lo introdujo como agente para la pulpotomía y fue denominado Calxyl. En los últimos dos decenios se ha hecho más popular en endodoncia y ha tenido éxito en diversas situaciones clínicas. Actualmente constituye un medicamento endodóntico eficaz ${ }^{2}$.

Según se ha citado, el hidróxido de calcio ha sido incluido en varios materiales y formulaciones antimicrobianas, usadas en un amplio número de modalidades de tratamientos en endodoncia ${ }^{3}$.

\section{Desarrollo}

El hidróxido de calcio es un polvo blanco producido por la mezcla de óxido de calcio ("cal") con agua. La intoxicación con hidróxido de calcio, ocurre cuando alguien ingiere esta sustancia. Es un polvo blanco que se obtiene por la calcinación del carbonato cálcico:

$$
\begin{aligned}
& \mathrm{CaCO}_{3}(\mathrm{~s})=\mathrm{CaO}(\mathrm{s})+\mathrm{CO}_{2}(\mathrm{~g}) \\
& \mathrm{CaO}(\mathrm{s})+\mathrm{H}_{2} \mathrm{O}=\mathrm{Ca}(\mathrm{OH})_{2}(\mathrm{ac})
\end{aligned}
$$


Es considerado como el medicamento de elección, tanto en la protección pulpar directa como indirecta, y pulpotomía vital. Como tiene tendencia a formar carbonato con el anhídrido carbónico $\left(\mathrm{CO}_{2}\right)$ del aire, se recomienda almacenarlo en un frasco color topacio bien cerrado. Es poco soluble en agua, su pH es alcalino, aproximadamente de 12.4, lo que le permite ser un magnífico bactericida, hasta las esporas mueren al ponerse en contacto con el elemento. Comúnmente se prepara con suero fisiológico ó agua tratada, aunque puede utilizarse cualquier presentación o marca comercial su fuente natural se relacionan a continuación: Cemento, Agua de cal. Muchos disolventes y limpiadores industriales (cientos de miles de productos de la construcción, raspadores de pisos, limpiadores de ladrillos, productos endurecedores del cemento y muchos otros) y Cal apagada ${ }^{4}$.

\section{Propiedades}

1. Estimula la calcificación, de una manera muy clara, activa los procesos reparativos por activación osteoblástica; al aumentar en $\mathrm{pH}$ en los tejidos dentales (Tronsland. 1981); cree que dicho cambio de pH es beneficioso porque además inhibe la actividad osteoclástica.

2. Antibacteriano. Kodukula en 1988, relata que las condiciones del elevado pH baja la concentración de iones de $\mathrm{H}+$; y la actividad enzimática de la bacteria es inhibida. Puede esterilizar hasta un $88 \%$ de los conductos radiculares (Cuek.1976).

3. Disminuye el edema.

4. Destruye el exudado.

5. Genera una barrera mecánica de cicatrización apical.

6. Sella el sistema de conductos (Mérida, 1985).

7. Equilibrada toxicidad al ser mesclado con solución fisiológica o anestesia.

8. Disminución de la sensibilidad (por su efecto sobre la fibra nerviosa).

9. Reducción de la inflamación de los tejidos periapicales. 
10. Controla el absceso periapical: mediante una disminución del exudado persistente en la zona apical.

11. Favorece la disolución del tejido pulpar, al combinar la acción del hidróxido de calcio con la irrigación de hipoclorito de sodio.

12. Previene la reabsorción inflamatoria radicular.

13. En conductos radiculares con anatomía compleja con múltiples zonas inaccesibles a la instrumentación y a la irrigación. Entre otras ${ }^{5}$.

\section{Modo de preparación}

Cuando el hidróxido de calcio se usa como medicación temporal intraconducto, se emplean preparados que no fraguan, y que se solubilizan y reabsorben en los tejidos vitales. El vehículo más usado para ser mezclado con el hidróxido de calcio es el agua destilada, aunque entre los más frecuentes también se encuentran la solución anestésica, clorhexidina, suero fisiológico, paramonoclorofenol alcanforado, yodoformo y propilenglicol.

\section{Propiedad antimicrobiana del hidróxido de calcio}

El fundamento básico para la selección del medicamento antimicrobiano ideal, para combatir las infecciones presentes en el conducto radicular y los tejidos periapicales, consiste en conocer su mecanismo de acción. La neutralización de los focos de agresión microbiana había sido delegado a la fase de la preparación mecánica, se ha demostrado que la preparación aislada no garantiza la completa recuperación por lo que se necesita aplicar un medicamento. En la historia de la fase medicamentosa de la endodoncia, se ha reportado el empleo de numerosos fármacos y se ha determinado que el fármaco ideal es el hidróxido de calcio, por ser inocuo, antimicrobiano y reparador ${ }^{6}$.

La explicación del mecanismo de acción del hidróxido de calcio en el control de la actividad enzimática bacteriana, está dada por su elevado $\mathrm{Ph}(12,6)$, influenciado por la liberación de iones hidroxilos, que son capaces de alterar la integridad de la membrana citoplasmática, a través de los daños en los componentes orgánicos y en el transporte de los nutrientes; así como también por medio 
de la destrucción de los fosfolípidos o ácidos grasos insaturados de la membrana citoplasmática, en el proceso de peroxidación lipídica, ocurriendo una reacción de saponificación? 7 .

Por consiguiente, el mecanismo de acción del hidróxido de calcio, a través de su Ph alcalino en el control de la actividad enzimática microbiana posibilita su inactivación reversible e irreversible, dependiendo justamente del tiempo en que esté en contactó con los micro-organismos, por lo tanto para que sea eficaz es imprescindible que el hidróxido de calcio actúe por un tiempo prolongado ${ }^{7}$.

El hidróxido de calcio es un excelente medicamento con efecto antimicrobiano, sin embargo se ha sugerido el empleo de numerosas vehículos para asociarlo, a fin de mejorar sus propiedades. Los factores que influencian la velocidad de disociación y difusión fónica son la hidrosolubilidad del vehículo empleado, las características de ácido-base, la permeabilidad dentinaria y el grado de calcificación. Mientras mayor es la velocidad de disociación y difusión de los iones hidroxilos de las pastas de hidróxido de calcio, mayor será el efecto antimicrobiano, lográndose esto con los vehículos hidrosolubles ${ }^{8}$.

Entre los vehículos hidrosolubles más utilizados tenemos: solución anestésica, solución fisiológica, agua destilada, hipoclorito de sodio, clorhexidina:

Con los conocimientos actuales de hidróxido de calcio, su uso como antimicrobiano es preferible al de otras sustancias, conociendo que reduce significativamente el crecimiento y desarrollo de los microorganismos tanto en el tejido dentario como en los tejidos subyacentes; además, asociado al nuevo diseño de los instrumentos endodónticos, se posibilita el auge de su uso como el "antimicrobiano ideal"8.

\section{Tratamiento del traumatismo}

Fracturas radiculares: el tratamiento inicial con $\mathrm{CaOH}$, tiene un pronóstico muy bueno, se recomienda la obturación del conducto radicular con el mismo, luego de haber sido alineados los fragmentos fracturados. En un estudio de dientes con fractura radicular se observó la curación periodontal en todos los tratados inicialmente con $\mathrm{CaOH}^{2}$.

Luxaciones y avulsiones: en las luxaciones se debe realizar el tratamiento endodóntico lo antes posible, rellenando el conducto con $\mathrm{CaOH}$, el cual se cambia mensualmente durante un año en los 
dientes con ápices formados y se realiza una técnica de Frank en dientes con ápices abiertos; en las avulsiones después de eliminada la pulpa y luego de siete a 14 días de ocurrida, se debe rellenar el conducto con $\mathrm{CaOH}$, se restablece cada tres meses durante un período entre 12 y 18 meses ${ }^{2}$.

En la reabsorción interna: en esta afección debido a la extensión del defecto no es posible remover todo el tejido granulado, el uso del $\mathrm{CaOH}$ por un período determinado produce el colapso del tejido de granulación restante. Una vez removido este tejido el defecto podrá ser tratado buscando la recalcificación con $\mathrm{CaOH}$. En caso de ocurrir una perforación de la raíz, a nivel del hueso, se produce una barrera de tejido duro si usamos este medicamento por un tiempo prolongado (12 meses) y posteriormente se hace la obturación del conducto ${ }^{2}$.

Para el tratamiento de lesiones endoperiodontales: luego de haber removido todas las bacterias y antígenos del canal infectado, el $\mathrm{CaOH}$ se usa para promover una rápida remisión de los defectos óseos, una pronta reinserción del ligamento periodontal, así como un cierre contra el medio bucal y el ingreso de microorganismos ${ }^{2}$.

En los cementos selladores de los conductos radiculares: se considera que el sellado biológico es la respuesta de la obturación del sistema de conductos radiculares; este es uno de los objetivos de la terapia de conductos. $\mathrm{El} \mathrm{CaOH}$ ha sido utilizado como sellador para el conducto radicular (cemento), combinado con algún material para rellenar el centro del conducto, como la gutapercha, ya que conserva la vitalidad del muñón pulpar y estimula la cicatrización y formación del tejido duro del agujero $^{2}$.

\section{Utilización del $\mathrm{CaOH}$ en la endodoncia preventiva}

1. El recubrimiento pulpar indirecto consiste en hacer actuar un medicamento sobre la pulpa todavía cubierta de dentina, de esta forma se conserva y estimula a la formación de dentina secundaria. El $\mathrm{CaOH}$ produce protección mediante sus propiedades antibacterianas y su capacidad para reducir la permeabilidad dentinaria, ningún fármaco tiene el poder dentinogénico del $\mathrm{CaOH}$ y aunque quede dentina alterada siempre será mejor la protección indirecta que la directa. También es usado en el tratamiento de la hipersensibilidad dentinaria; como base intermedia bajo restauraciones permanentes y como revestimiento o forro cavitario. 
2. En el recubrimiento pulpar directo, el hidróxido de calcio es el agente ideal para el tratamiento de las pulpas expuestas. Dycal, Life, Pulpdent entre otras, son pastas de $\mathrm{CaOH}$ eficaces para la conservación de la vitalidad pulpar, mientras permiten la reparación del tejido duro en el sitio de la lesión. En las pulpotomías coronales, útiles en la apicogénesis de dientes permanentes parcialmente desarrollados donde la exposición pulpar es amplia y no se ha podido controlar el factor microbiano, en pulpitis transitorias o pulpitis crónicas irreversibles, siempre que la formación radicular es incompleta se recomienda el uso del $\mathrm{CaOH}$. La extirpación del tejido pulpar vital lesionado, generalmente el coronario, es necesaria para preservar el tejido radicular expuesto. Otra de las técnicas encontradas es el curetaje pulpar, que consiste en la estricta remoción de la pulpa enferma cuando un cuerno pulpar es expuesto accidentalmente durante las maniobras operatorias en la remoción del tejido cariado, permanece el resto de la pulpa intacta y recubierta con $\mathrm{CaOH}^{9,2}$.

Silva-Herzog et $\mathrm{al}^{10} \mathrm{y}$ colaboradores señalaron que de los cuatro vehículos investigados: propilenglicol, polietilenglicol 400, glicerol y suero fisiológico, a diferentes tiempos $(24 \mathrm{~h}, 7,15$, y 30 días), el que mostró mejor comportamiento al combinarse con el $\mathrm{Ca}(\mathrm{OH}) 2$ fue el propilenglicol, presentando una liberación mayor de iones calcio de $580 \mathrm{ppm}$ a los 7 días, seguido por el polietilenglicol con una liberación de $280 \mathrm{ppm}$, en tanto que el suero fisiológico presentó $270 \mathrm{ppm}$, finalmente el glicerol sólo liberó 16.6 ppm.

El objetivo de todo tratamiento conservador en un diente vital, es mantenerlo sano y en estado funcional. Sin embargo, después de la caries dental la causa más frecuente de daño pulpar es la iatrogenia introducida por el odontólogo debido al uso inadecuado de los materiales y a la aplicación incorrecta de las técnicas de tratamiento. En un estudio se señala que el recubrimiento pulpar directo, sería una opción terapéutica valida, ante la exposición pulpar producida durante un procedimiento clínico restaurador, como un medio de mantener la vitalidad de la pieza dentaria, siempre y cuando el clínico se guíe por sus estrictas indicaciones de tratamiento. La formación de puente dentinario se asocia positivamente al éxito de los recubrimientos pulpares directos ${ }^{11}$.

Otros autores demostraron que la utilización de un protocolo de irrigación final que combine hipoclorito de sodio como solución irrigante, EDTA como quelante y energización ultrasónica es el método más eficaz para remover la pasta de $\mathrm{Ca}(\mathrm{OH})_{2}$ de las paredes del conducto. Esto influye 
favorablemente en el sellado apical, ya que propicia condiciones adecuadas para lograr la adaptación de los materiales de obturación al sistema de conductos radiculares ${ }^{12}$.

Para dar por concluido, el papel del hidróxido de calcio en endodoncia incluye su propiedad para inducir la formación de tejido duro, su incidencia para causar oclusión intratubular, sus acciones antibacterianas, y su capacidad de disolución tisular.

\section{Bibliografía}

1- Pérez González K. Eficacia de los protectores pulpares a base de ionómero de vidrio e hidróxido de calcio en la formación de dentina reparadora. 2015. Trabajo de titulación previo a la obtención del título de odontólogo, [citado 22 agosto 2017]. Disponible en: repositorio.ug.edu.ec/handle/redug/17834

2- Rodríguez Gutiérrez Genné, Álvarez Llanes Marina, García Boss Joel, Arias Herrera Sury R., Más Sarabia Maheli. El hidróxido de calcio: su uso clínico en la endodoncia actual. AMC. 2005 [citado 22 agosto 2017]; 9 (3): 143-152. Disponible en: http://scielo.sld.cu/scielo.php?script=sci_arttext\&pid=S1025-02552005000300016\&lng=es

3- Mohamaddi Z. y Dummer P. Properties and applications of calcium hydroxide in endodontics and dental traumatology. International Endodontic Journal, 2011; 44(8): 697-730

4 Hidróxido de calcio. EcuRed. Enciclopedia colaborativa Cubana 2017, [citado 22 agosto 2017]. Disponible en: https://www.ecured.cu/Hidr\%C3\%B3xido_de_Calcio

5- Rodríguez Benítez S. Importancia del hidróxido de calcio como medicamento intraconducto en Endodoncia. A propósito de un caso clínico. Revista Gaceta Dental.2009, [citado 22 agosto 2017]. Disponible en https://www.gacetadental.com/2009/03/importancia-del-hidrxido-decalcio-como-medicamento-intraconducto-en-endodoncia-a-propsito-de-un-caso-clnico$31678 /$

6- Champa Yanac, Yackeline Ericka. Actividad antimicrobiana del hidróxido de calcio asociado a distintos vehículos como medicación intraconducto frente a bacterias aisladas de dientes con Periodontitis Apical Asintomática. 2017, [citado 22 agosto 2017]. Disponible en http://cybertesis.unmsm.edu.pe/xmlui/handle/cybertesis/6183 
7- Estrela, C.; Sydney y otros. EDTA effect at root dentin Ph then exchange of Calcium Hydroxide paste. Braz. Endod. J, 1997; 2 (1): 12-17

8- Romero Méndez Y. Propiedad antimicrobiana del hidróxido de calcio. Revista de la Facultad de Odontologia de Camacho, 2015. [citado 22 agosto 2017]. Disponible en servicio.bc.uc.edu.ve/odontologia/revista/v2n1/2-1-6.pd

9- Sosa Rosales M de la C. Guías prácticas clínicas de estomatología. La Habana: Editorial Ciencias Médicas; 2003

10- Silva-Herzog F D,* Andrade Velásquez L, Lainfiesta Rímola J. Comparación del hidróxido de calcio como medicamento intraconducto, utilizando vehículos viscosos y acuosos. Estudio in vitro. Revista ADM. 2005. Vol. LXII, No. 4 pp 137-141

11- Contreras Gallardo G. Estudio retrospectivo de los tratamientos de recubrimiento pulpar directo realizados en clínica de operatoria dental, casos entre 1999-2005.2007. Trabajo de investigación, requisito para optar al título de Cirujano-Dentista. Universidad de chile facultad de odontologia. [citado 22 agosto 2017]. Disponible en repositorio.uchile.cl/.../Estudiorestrospectivo-de-los-tratamientos-de-recubrimiento-p

12- Sánchez Ortega Jeannette, Guerrero Jorge, Elorza Haroldo, García Aranda Raúl Luis. Influencia del hidróxido de calcio como medicación intraconducto en la microfiltración apical. Rev. Odont. Mex. 2011 [citado 22 agosto 2017]; 15 (4): 224-230. Disponible en: http://www.scielo.org.mx/scielo.php?script=sci_arttext\&pid=S1870199X2011000400004\&lng=es 